\title{
Desempenho de bezerros holandeses alimentados até o desaleitamento com silagem de grãos úmidos ou grãos secos de milho ou sorgo ${ }^{1}$
}

\section{Gercílio Alves de Almeida Júnior², Ciniro Costa ${ }^{3}$, Sebastião Marcos Ribeiro de Carvalho 4 , Amanda Panichi ${ }^{5}$, Pedro Persichetti Júnior ${ }^{5}$}

\footnotetext{
${ }^{1}$ Projeto financiado pela Unimar - Universidade de Marília e UNESP.

2 Departamento de Zootecnia da Faculdade de Ciências Agrárias - Universidade de Marília, CEP: 17525-902, Marília, SP.

${ }^{3}$ Departamento de Melhoramento e Nutrição Animal da FMVZ-UNESP, Botucatu, SP.

${ }^{4}$ Programa de Pós-Graduação em Agronomia da Faculdade de Ciências Agrárias da Universidade de Marília.

${ }^{5}$ Curso de Graduação em Zootecnia - Unimar.
}

RESUMO - Avaliou-se o desempenho de bezerros alimentados até o desaleitamento com silagem de grãos úmidos ou grãos secos de milho ou sorgo para posterior produção de vitelos de carne rosa. Trinta bezerros holandeses foram distribuídos em delineamento em blocos casualizados, com cinco blocos e seis tratamentos, e alimentados com seis rações concentradas com teores similares de proteína (22,5\% PB) e de energia (3,2 Mcal EM/kg MS), formuladas com: milho seco moído (MM); silagem de grãos úmidos de milho (SGUM); sorgo seco com tanino moído (SCTM); silagem de grãos úmidos de sorgo com tanino (SGUSCT); sorgo seco sem tanino moído (SSTM); e silagem de grãos úmidos de sorgo sem tanino (SGUSST). Os animais receberam sucedâneo de leite até atingirem o peso pré-estabelecido para desaleitamento (60 $\pm 5 \mathrm{~kg}$ ). Não houve efeito das rações concentradas sobre a altura de cernelha, a idade ao desaleitamento, os consumos diários de MS diários e totais das rações concentradas, os ganhos de peso diários e totais e a conversão alimentar. Os custos por kg de ganho de peso das rações concentradas contendo sorgo foram mais baixos que o das rações concentradas formuladas com milho. Todos os alimentos avaliados podem ser usados em rações concentradas para bezerros em fase de aleitamento, pois não comprometem o desempenho e conferem resultados similares.

Palavras-chave: custos de produção, sucedâneo, tanino, vitelos

\section{Performance of Holstein calves fed until weaning time with high moisture grains silage or dry ground grains of corn or sorghum}

\begin{abstract}
The performance of calves fed until weaning time with high moisture grains silage or dry ground grains of corn or sorghum was evaluated, for posterior production of pink meat veal. Thirty Holstein calves were allotted to a complete randomized blocks experimental design with five blocks and six treatments, fed with six concentrate rations with similar contents of protein (22.5\% CP) and energy (3.2 Mcal ME/kg DM) formulated with: dry ground corn (GC), high moisture corn silage (HMCS), dry ground sorghum with tannin (GSWT), high moisture sorghum with tannin silage (HMSWTS), dry ground sorghum without tannin (GSWTT) or high moisture sorghum without tannin silage (HMSWTTS). The animals received milk replacer until reaching the fixed weight for weaning $(60 \pm 5 \mathrm{~kg})$. No treatment effects were observed on shoulder height, age at weaning time, daily and total DM intakes of the concentrate rations, daily and total weight gains and feed:gain ratio. Costs per $\mathrm{kg}$ of weight gain of the concentrate rations containing sorghum were lower as compared with concentrate rations formulated with corn. All evaluated feeds could be used in concentrate rations for calves in nursing phase, because they do not impair performance and confer similar results.
\end{abstract}

Key Words: milk replacer, production costs, tannin, veal calves

\section{Introdução}

Uma das fases mais críticas na criação de bezerros com predominância de genética taurina é a fase inicial ou de aleitamento, tanto pelo aspecto econômico (Teixeira et al., 1999) com pelo aspecto técnico. Nesta fase, são comuns os problemas decorrentes de má imunização por baixa ingestão de colostro ou exposição espoliativa a endo e ectoparasitas, o que incorre em elevados índices de morbidez e mortalidade.

Normalmente, os machos, por não apresentarem o valor comercial das fêmeas nos rebanhos leiteiros especializados, são mais susceptíveis a problemas nessa fase por terem pouca ou nenhuma ingestão de colostro, o que aumenta 
excepcionalmente os riscos de doenças e mortalidade (Machado Neto et al., 2004a), tornando-se um grande problema para o produtor que desejar se especializar na produção de vitelos com aquisição de animais de outros plantéis.

Os bezerros precisam ser estimulados o mais cedo possível a ingerirem alimentos concentrados, uma vez que o consumo é o fator mais importante para o desenvolvimento do rúmen e da flora microbiana e para a transição da fase de pré-ruminante a ruminante, de modo a permitir que o animal seja desaleitado precocemente (Anderson et al., 1987).

Nussio et al. (2003a) destacaram a importância da ingestão de alimentos concentrados que produzem na sua fermentação principalmente os ácidos graxos voláteis (AGV) propiônico e butírico para o desenvolvimento de papilas ruminais em bezerros. Esses autores destacaram que, entre os principais AGV produzidos no rúmen, o ácido butírico é o principal para o crescimento em número e tamanho de papilas, seguido pelo ácido propiônico, enquanto o ácido acético tem pouca importância.

Outro aspecto importante é que o custo da ração concentrada para bezerros, embora seja composta de ingredientes nobres, com baixos teores de fibra e elevados níveis energéticos, quase sempre é menor que o dos sucedâneos utilizados no aleitamento. Além disso, a partir do momento em que os animais apresentam satisfatório consumo de concentrados, o alimento líquido (leite ou sucedâneo) passa a ter menos importância na ingestão de MS e no desempenho animal, o que permite seu desaleitamento e a conseqüente diminuição dos custos na criação.

Portanto, é importante a avaliação de alimentos energéticos alternativos ao milho moído que confiram viabilidade técnica e econômica em uma criação comercial de vitelos nas condições brasileiras de produção. Nesse contexto, o sorgo, por possuir características nutritivas semelhantes e preços inferiores ao do milho, pode constituir opção viável (Duarte, 2002).

Como as silagens de grãos úmidos geralmente apresentam menores custos e maior digestibilidade do amido em comparação a silagens de grãos secos moídos (Almeida Jr. et al., 2004), a avaliação dos impactos de seu uso na alimentação de bezerros pré-ruminantes ou em início de ruminação é de grande interesse.

Neste trabalho, avaliaram-se os efeitos do fornecimento de milho ou sorgo nas formas de silagem de grãos úmidos ou de grãos secos moídos sobre o desempenho de bezerros holandeses até o desaleitamento para produção de vitelos de carne rosa.

\section{Material e Métodos}

O experimento foi conduzido no Setor de Bovinocultura de Leite da Universidade de Marília, em Marília, SP, onde foram avaliadas seis rações contendo: milho seco moído (MM); silagem de grãos úmidos de milho (SGUM); sorgo seco com tanino moído (SCTM); silagem de grãos úmidos de sorgo com tanino (SGUSCT); sorgo seco sem tanino moído (SSTM); e silagem de grãos úmidos de sorgo sem tanino (SGUSST).

Foram utilizados 30 bezerros holandeses (HPB) PO e PC do plantel próprio e de outros plantéis da região com idade média inferior a 5 dias, distribuídos nos seis tratamentos, totalizando cinco animais por tratamento. O peso pré-estabelecido para o desaleitamento dos bezerros foi de $60 \pm 5 \mathrm{~kg} P V$, desde que apresentassem boas condições gerais e consumo de ração superior a $1 \mathrm{~kg}$ MS/dia.

Os bezerros foram criados em abrigos individuais móveis do tipo casinha tropical (modelo Embrapa-CPPSE), com 1,35 m de altura, 1,45 m de profundidade e 1,00 m de largura, cobertos com telha de zinco, sem paredes laterais, e fechados no fundo para proteção do cocho de ração contra chuvas e sol. Os animais foram contidos nos abrigos, dotados cada um de bebedouro plástico externo para $5 \mathrm{~L}$, por meio de correntes de $2 \mathrm{~m}$ com coleiras de couro em sistema de mosquetão. Como material de cama utilizou-se feno de coastcross de qualidade inferior, renovado a cada dois ou três dias, de acordo com sua condição.

Nos três primeiros dias de vida, os bezerros receberam $4 \mathrm{~L}$ de colostro de forma integral, divididos em duas porções eqüitativas; a partir daí, foram aleitados com $2 \mathrm{~L}$ de sucedâneo de leite pela manhã e $2 \mathrm{~L}$ à tarde até completarem sua primeira semana no experimento. A partir do oitavo dia, receberam $3 \mathrm{~L}$ pela manhã e $2 \mathrm{~L}$ à tarde até completarem 40 dias no experimento, quando passaram a receber, até o desaleitamento, apenas $3 \mathrm{~L} /$ dia no período da manhã com o objetivo de estimular o consumo de ração no período da tarde e à noite. A solução de sucedâneo com 25\% de lactose (Bovilac ${ }^{\circledR}$ ) foi preparada em recipiente de aço inox aquecido em fogareiro a gás até $37^{\circ} \mathrm{C}$, na proporção de uma parte de pó para nove partes de água.

A água e as rações concentradas foram oferecidas ad libitum duas vezes ao dia a partir da chegada dos animais. As sobras das rações foram pesadas antes de cada novo fornecimento. As seis rações (Tabela 1) continham teores similares de proteína (22,5\% PB na MS) e energia (3,2 Mcal EM/kg de MS). Não houve fornecimento de feno como alimento. 
As matérias-primas foram analisadas periodicamente. Observaram-se teores de 0,95 e $0,37 \%$ de tanino para os sorgos com e sem tanino, respectivamente. De acordo com Butolo (2002), percentuais abaixo de $0,70 \%$ no grão estão relacionados a outros compostos fenólicos, e não ao tanino condensado, portanto, trata-se de sorgo sem tanino. Os valores obtidos para a energia metabolizável foram obtidos segundo o NRC (1988):

$$
\mathrm{EM}=-0,45+1,01 \mathrm{ED} \text {, }
$$

em que ED (energia digestível) = 0,04409 $\times$ NDT $(\%)$.

O milho (semidentado - C 333B) e os sorgos utilizados na silagem de grãos úmidos foram produzidos na Fazenda Lageado da UNESP em Botucatu, onde foram confeccionadas todas as silagens de grãos úmidos, em tambores plásticos de 100 L. O milho usado para moagem com grãos secos foi do tipo duro (“flint”), adquirido no comércio de Marília. O sorgo com tanino usado como grãos secos moídos ou silagem de grãos úmidos foi o BR 701 e o sorgo sem tanino foi o AG 1018. Os grãos secos de milho e sorgo foram moídos em moinho de martelos, modelo 9135/408 RDE - Silver, com peneira de $3 \mathrm{~mm}$, e o farelo de soja foi o integral com grãos tostados (Tabela 2).

Todos os animais foram identificados por meio de brincos, pesados e mensurados na cernelha no dia de sua chegada. A cada 14 dias, foram feitas novas pesagens e mensurações. Os bezerros não foram castrados nem mochados e foram vacinados aos 30 e aos 60 dias de idade contra clostridioses (Polivalente Sintoxan ${ }^{\circledR}$ ). O cordão umbilical foi cortado a dois dedos de sua inserção no abdômen e foi curado com solução iodada até sua completa

Tabela 1 - Composição percentual dos ingredientes das rações concentradas (\% MS)

\begin{tabular}{|c|c|c|c|c|c|c|}
\hline \multirow[t]{2}{*}{ Ingrediente } & \multicolumn{6}{|c|}{ Ração concentrada } \\
\hline & $\mathrm{MM}$ & SGUM & SCTM & SGUSCT & SSTM & SGUSST \\
\hline Milho seco moído & 60,10 & & & & & \\
\hline $\mathrm{SGU}^{1}$ de milho & & 58,40 & & & & \\
\hline Sorgo seco com tanino moído & & & 61,70 & & & \\
\hline SGU de sorgo com tanino & & & & 60,50 & & \\
\hline Sorgo seco sem tanino moído & & & & & 62,30 & \\
\hline SGU de sorgo sem tanino & & & & & & 62,30 \\
\hline Farelo de soja & 30,20 & 31,90 & 28,60 & 29,80 & 28,00 & 28,00 \\
\hline Palatabilizante/aromatizante ${ }^{2}$ & 5,20 & 5,20 & 5,20 & 5,20 & 5,20 & 5,20 \\
\hline Núcleo mineral vitamínico ${ }^{3}$ & 4,50 & 4,50 & 4,50 & 4,50 & 4,50 & 4,50 \\
\hline
\end{tabular}

1 Silagem de grãos úmidos.

2 Leitemix ${ }^{2}$.

3 Núcleo Bovino Nutron Bezerro Cromo®: 25\% Ca; 6,5\% P; 4,9\% Na; 875 mg/kg de monensina sódica e 25 ppm Cr.

MM - milho seco moído; SGUM - silagem de grãos úmidos de milho; SCTM - sorgo seco com tanino moído, SGUSCT - silagem de grãos úmidos de sorgo com tanino; SSTM - sorgo seco sem tanino moído, SGUSST - silagem de grãos úmidos de sorgo sem tanino.

Tabela 2 - Composição química do sucedâneo, dos ingredientes e das rações concentradas (\% MS)

\begin{tabular}{|c|c|c|c|c|c|c|c|c|c|}
\hline Item & MS & PB & $\mathrm{EE}$ & FDN & FDA & $\mathrm{EM}^{1}$ & Cinzas & $\mathrm{Ca}$ & $\mathrm{P}$ \\
\hline \multicolumn{10}{|l|}{ Ingrediente } \\
\hline Sucedâneo & 92,00 & 21,74 & 13,04 & - & - & 3,58 & 16,30 & 0,87 & 0,43 \\
\hline Farelo de soja & 90,47 & 51,46 & 0,94 & 16,96 & 11,88 & 3,03 & 7,11 & 0,29 & 0,61 \\
\hline Palatabilizante $^{2}$ & 92,00 & 21,74 & 10,33 & - & - & 3,74 & 2,17 & 0,11 & 0,33 \\
\hline $\mathrm{MM}$ & 90,17 & 9,50 & 5,12 & 16,17 & 4,52 & 3,22 & 1,44 & 0,06 & 0,29 \\
\hline SGUM & 73,91 & 9,01 & 3,79 & 7,92 & 3,09 & 3,18 & 1,34 & 0,03 & 0,26 \\
\hline SCTM & 88,70 & 10,84 & 3,61 & 18,45 & 8,92 & 3,13 & 1,81 & 0,04 & 0,28 \\
\hline SGUSCT & 74,42 & 10,30 & 3,30 & 8,24 & 6,27 & 3,13 & 1,64 & 0,05 & 0,25 \\
\hline SSTM & 89,32 & 11,25 & 3,60 & 17,85 & 5,51 & 3,13 & 1,43 & 0,04 & 0,26 \\
\hline SGUSST & 69,00 & 11,66 & 4,27 & 6,05 & 3,02 & 3,19 & 1,37 & 0,06 & 0,20 \\
\hline \multicolumn{10}{|c|}{ Ração concentrada } \\
\hline MM & 90,75 & 22,38 & 4,10 & 14,84 & 6,30 & 3,26 & 7,63 & 1,25 & 0,67 \\
\hline SGUM & 80,37 & 22,81 & 3,26 & 10,03 & 5,59 & 3,22 & 7,66 & 1,24 & 0,65 \\
\hline SCTM & 89,82 & 22,54 & 3,22 & 16,23 & 8,90 & 3,20 & 7,76 & 1,24 & 0,66 \\
\hline SGUSCT & 80,40 & 22,70 & 3,01 & 10,04 & 7,33 & 3,20 & 7,72 & 1,24 & 0,64 \\
\hline SSTM & 90,21 & 22,55 & 3,23 & 15,87 & 6,76 & 3,20 & 7,49 & 1,24 & 0,64 \\
\hline SGUSST & 76,11 & 22,80 & 3,65 & 8,51 & 5,21 & 3,27 & 7,46 & 1,25 & 0,60 \\
\hline
\end{tabular}

1 Energia metabolizável (Mcal/kg MS).

2 Núcleo palatabilizante e aromatizante.

MM - milho seco moído; SGUM - silagem de grãos úmidos de milho; SCTM - sorgo seco com tanino moído, SGUSCT - silagem de grãos úmidos de sorgo com tanino; SSTM - sorgo seco sem tanino moído, SGUSST - silagem de grãos úmidos de sorgo sem tanino. 
secagem, queda e cicatrização. O controle de infecções parasitárias foi feito com aplicações de ivermectina a 1\% (Iverbion ${ }^{\circledR}$ ) em todos os animais no dia de entrada no experimento, procedendo-se a outra aplicação no dia do desaleitamento.

Eventuais controles carrapaticidas foram feitos por meio de pulverizações com Neguvon Asuntol ${ }^{\circledR}$ Plus, quando necessários, e os casos de diarréia foram medicados com antidiarréicos comerciais, de acordo com a etiologia de cada ocorrência.

Para a análise dos custos dessa fase da criação, foram considerados os preços de mercado para os ingredientes e avaliados apenas os custos operacionais efetivos com alimentação e sanidade, componentes de alta representatividade no custo total desses animais. Não foram considerados os custos fixos inerentes às depreciações de instalações e equipamentos nem os custos com aquisição de bezerros e mão-de-obra. Os resultados da análise de custos não foram avaliados estatisticamente.

O delineamento experimental adotado foi o de blocos casualizados, com cinco blocos e seis tratamentos com cinco repetições por tratamento, e a comparação entre os grupos foi realizada por meio de análise de variância com um fator, complementada pelo teste Tukey utilizando-se para os cálculos o Programa Computacional SANEST (IAC, 1992). Os blocos foram estabelecidos de modo a controlar entre os seis tratamentos os efeitos de local e de época de entrada.

\section{Resultados e Discussão}

Os animais alimentados com as diferentes rações experimentais apresentaram pesos, idades e alturas iniciais similares, além de condições bem homogêneas. O peso e altura iniciais médios dos animais no experimento foram de 39,92 kg e 77,10 cm, mas, considerando que houve bezerros filhos de primíparas em todos os tratamentos, pode-se assumir que os valores foram compatíveis com os padrões da raça. A Associação Brasileira dos Criadores de Bovinos da Raça Holandesa indica peso de $45 \mathrm{~kg}$ e altura de $82 \mathrm{~cm}$ como padrões para os machos ao nascimento (ABCBRH, 2005).

Não houve efeito $(\mathrm{P}>0,05)$ da composição das rações sobre o peso, a altura de cernelha, a idade, o consumo, o ganho de peso e a conversão alimentar (Tabela 3). O peso e a altura finais dos bezerros não diferiram $(\mathrm{P}>0,05)$ entre as rações e apresentaram médias de $64,14 \mathrm{~kg}$ e $84,97 \mathrm{~cm}$. A idade final média também foi similar $(\mathrm{P}>0,05)$ entre os animais (66,63 dias). Modesto et al. (2002), avaliando dietas líquidas para bezerros holandeses, também não encontraram diferenças $(\mathrm{P}>0,10)$ na altura de cernelha aos 60 dias de vida dos animais e verificaram média de $84,05 \mathrm{~cm}$.

O peso médio obtido foi menor que o observado por Signoretti et al. (1999), que citaram peso de $78 \mathrm{~kg}$ para bezerros holandeses desaleitados aos 60 dias. No entanto, esses autores não indicaram o sistema de aleitamento adotado. Em outro experimento para produção de vitelos, Ribeiro et al. (2001) relataram peso médio de $76 \mathrm{~kg}$ aos 75 dias de idade para animais desaleitados aos 60 dias com sucedâneo de leite. Esses resultados indicam que esses animais têm potencial para ganhos diários e totais superiores aos obtidos neste experimento, que também não diferiram entre si $(\mathrm{P}>0,05)$ e apresentaram médias $390 \mathrm{~g} \mathrm{e}$ $24,22 \mathrm{~kg}$, respectivamente.

A falta de controle da ingestão individual de colostro nos bezerros provenientes de outras propriedades e o fornecimento de sucedâneo contendo amido de milho prégeleificado em substituição parcial à lactose, que seria a

Tabela 3 - Desempenho dos bezerros alimentados com as rações concentradas

\begin{tabular}{|c|c|c|c|c|c|c|c|c|c|}
\hline \multirow[t]{2}{*}{ Item } & \multicolumn{6}{|c|}{ Ração concentrada } & \multirow[t]{2}{*}{ Média } & \multirow[t]{2}{*}{$\mathrm{CV} \%$} & \multirow[t]{2}{*}{ Valor de $\mathrm{P}$} \\
\hline & MM & SGUM & SCTM & SGUSCT & SSTM & SGUSST & & & \\
\hline Peso inicial (kg) & 39,48 & 39,68 & 40,30 & 40,18 & 38,22 & 41,64 & 39,92 & - & - \\
\hline Peso final (kg) & 62,14 & 62,92 & 64,64 & 65,52 & 66,50 & 63,12 & 64,14 & 9,28 & $\mathrm{~ns}^{1}$ \\
\hline Altura da cernelha inicial $(\mathrm{cm})$ & 76,60 & 77,00 & 78,20 & 77,60 & 76,40 & 76,80 & 77,10 & - & - \\
\hline Altura da cernelha final (cm) & 83,80 & 83,60 & 85,80 & 85,80 & 85,80 & 85,00 & 84,97 & 2,66 & ns \\
\hline Idade inicial (dias) & 3,60 & 3,80 & 5,80 & 4,60 & 5,40 & 5,40 & 4,77 & - & - \\
\hline Idade final (dias) & 65,80 & 67,60 & 66,40 & 67,00 & 69,20 & 63,80 & 66,63 & 17,10 & ns \\
\hline Consumo total sucedâneo (L) & 267,70 & 285,10 & 254,30 & 276,60 & 277,70 & 254,40 & 269,30 & 16,34 & ns \\
\hline Consumo total ração (kg MS) & 35,96 & 33,45 & 41,08 & 30,03 & 43,84 & 26,23 & 35,10 & 29,60 & ns \\
\hline Ganho de peso vivo diário (kg) & 0,36 & 0,36 & 0,40 & 0,41 & 0,44 & 0,37 & 0,39 & 32,16 & ns \\
\hline Ganho de peso vivo total (kg) & 22,66 & 23,24 & 24,34 & 25,34 & 28,28 & 21,48 & 24,22 & 29,52 & ns \\
\hline Conversão alimentar (kg MS:kg GPV²) & 2,67 & 2,57 & 2,65 & 2,19 & 2,45 & 2,31 & 2,47 & 25,17 & ns \\
\hline
\end{tabular}

MM - milho seco moído; SGUM - silagem de grãos úmidos de milho; SCTM - sorgo seco com tanino moído; SGUSCT - silagem de grãos úmidos de sorgo com tanino; SSTM - sorgo seco sem tanino moído; SGUSST - silagem de grãos úmidos de sorgo sem tanino.

${ }^{1}$ Não-significativo - $\mathrm{P}>0,05 ;{ }^{2}$ Ganho de peso vivo. 
fonte energética ideal para esses animais desde o início do experimento, talvez possam justificar esse menor desempenho.

A utilização de sucedâneos com viabilidade técnica e econômica é um desafio, pois produtos de qualidade superior com maiores teores de derivados lácteos usualmente apresentam preços bem mais elevados e, por isso, são preferencialmente destinados à alimentação das bezerras.

Em revisão sobre o assunto, Bagaldo et al. (2006) observaram que bezerros alimentados com sucedâneo a partir da quarta semana de vida têm maiores chances de apresentar desempenhos similares aos de animais alimentados com leite. Nas primeiras semanas de vida dos bezerros, neste experimento, observou-se maior incidência de diarréias, estagnação e eventual perda de peso.

Machado Neto et al. (2004b) avaliaram o desempenho de bezerros de plantéis leiteiros e concluíram que diversos fatores, como tamanho do rebanho, manejo de colostro e aleitamento, local de criação dos animais, idade de acesso ao concentrado e período de desaleitamento, estão envolvidos no sistema de criação e podem determinar seu êxito ou fracasso.

Outros trabalhos avaliando aspectos como níveis mínimos de imunoglobulinas ingeridas via colostro, substituição escalonada ou brusca, total ou parcial do leite por sucedâneo, diferentes composições e custos de sucedâneos, temperatura e forma de preparo, fornecimento da dieta líquida, composição de ração concentrada e outros precisariam ser conduzidos para que fossem encontradas alternativas de produção que otimizem o desempenho inicial desses animais sem perda de viabilidade econômica.

Neste experimento foram avaliadas duas fontes de amido nas rações concentradas: o milho e o sorgo. O sorgo apresenta menor digestibilidade do amido em virtude de diferenças na relação amilose : amilopectina (quanto maior o teor de amilose, menor a digestibilidade do amido) e também por causa da natureza da matriz protéica que envolve os grânulos de amido do cereal (Owens et al., 1986; Huntington, 1997). Segundo Theurer (1986) e Simas (1998), cereais que, semelhantemente ao sorgo, naturalmente conferem menor digestibilidade ruminal do amido requerem maior intensidade de processamento dos grãos e são muito mais beneficiados pelas técnicas de processamento que os cereais que possuem naturalmente maior digestibilidade do amido.

Nesse sentido, as silagens de grãos úmidos, além de favorecerem a digestão ruminal do amido, também favorecem a produção de $\mathrm{AGV}$ no rúmen e, conseqüentemente, promovem melhor e mais rápido desenvolvimento do rúmen na fase inicial de vida dos ruminantes.
No entanto, essa expectativa não se cumpriu neste experimento, uma vez que os alimentos fornecidos conferiram resultados de desempenho semelhantes $(\mathrm{P}>0,05)$. Embora a silagem de grãos úmidos aumente a digestibilidade do amido em ruminantes adultos, em pré-ruminantes esses benefícios talvez não sejam tão pronunciados pelo fato de a digestão ainda ser predominantemente química e enzimática no abomaso e intestino delgado, o que, associado à magnitude do consumo de MS via sucedâneo nessa fase (Almeida Jr. et al., 2004), talvez justifique o fato de os animais alimentados com silagens de grãos úmidos não terem apresentado desempenhos superiores ao daqueles alimentados com grãos secos moídos. O consumo de MS de sucedâneo representou $41,4 \%$ do consumo total de MS pelos bezerros neste experimento.

Nussio et al. (2003b) não encontraram diferenças entre tratamentos em experimento com bezerras alimentadas com milho floculado ou laminado e também propuseram que o processamento de grãos pode não ser tão importante para um animal com o rúmen em desenvolvimento como para um animal ruminante funcional, uma vez que o animal préruminante tem digestão semelhante à de um monogástrico.

Outro aspecto que pode influenciar os efeitos do processamento de grãos na dieta de bezerros foi destacado por Bagaldo et al. (2006), que observaram que bezerros mastigam muito mais o alimento que bovinos adultos, o que poderia anular os efeitos benéficos do processamento dos grãos. Esses autores avaliaram a utilização de milho sob três densidades de floculação em rações para bezerros holandeses alimentados com dieta líquida de sucedâneo ou de leite durante a fase inicial e também não notaram efeito do processamento do miho sobre o desempenho dos animais. Contudo, o desempenho dos animais alimentados com sucedâneo foi menor $(\mathrm{P}<0,01)$ que o dos animais alimentados com leite.

As rações contendo sorgo com tanino também não promoveram resultados diferentes das rações contendo sorgo sem tanino. O tanino é um composto fenólico que confere defesa química ao grão do sorgo contra o ataque de pássaros, insetos e fungos, mas diminui a aceitabilidade e a digestibilidade da MS total da dieta e, sobretudo, da proteína por se complexar a ela precipitando-a, principalmente em monogástricos (Butolo, 2002). Assim, é possível que o fornecimento precoce de sucedâneo, por provocar maior incidência de diarréia e baixo consumo de MS, tenha contribuído para atenuar eventuais diferenças não só de digestibilidade entre milho e sorgo, grãos secos moídos e grãos úmidos, mas também de presença ou ausência de tanino.

Os consumos médios diários e totais de sucedâneo (4,39 e 269,30 l) e rações concentradas ( 0,57 e 35,10 kg MS) 
não diferiram entre si $(\mathrm{P}>0,05)$ e indicam que os alimentos avaliados também não afetaram a aceitabilidade das rações, inclusive o sorgo com alto teor de tanino na forma de grãos secos moídos ou silagem de grãos úmidos. Nussio et al. (2003b) também não encontraram diferenças $(P>0,05)$ no consumo em bezerras holandesas desaleitadas à sexta semana de vida alimentadas com dieta líquida de leite e rações contendo milho floculado ou laminado.

Uma vez que o consumo e o desempenho dos animais não foram influenciados pelas rações, também não houve diferença entre as rações $(\mathrm{P}>0,05)$ para a conversão alimentar dos bezerros, que apresentou valor médio de 2,47, considerado bom por Campos et al. (1996), que relataram conversões de 2,61 kg MS : kg GP para bezerros holandeses inteiros alimentados com sucedâneo até os 49 dias e 2,86 dos 50 aos 70 dias de idade. Bagaldo et al. (2006) também relataram conversão de 2,60 para animais desaleitados aos 49 dias com sucedâneo.

Para determinação dos custos das dietas, foram considerados os preços médios de mercado por ocasião do experimento para os ingredientes das rações, do sucedâneo e do gás. Como não foram determinados os custos de produção das silagens de grãos úmidos, assumiu-se o valor de $90 \%$ do preço do milho moído, em concordância com Almeida Jr. et al. (2004), que indicaram como referência os valores de 85 a 95\% do preço do milho moído no mercado nacional. Esses autores destacaram que as silagens de grãos úmidos tendem a ter menores custos que seus respectivos grãos secos, pois dispensam práticas de pré-limpeza e secagem, gastos com estocagem em silos graneleiros e fretes para o transporte e ainda apresentam menores perdas de MS e isenção de contribuições rurais.

Considerando o preço de mercado do milho moído ( $\mathrm{R} \$ 317,00 / t$ de matéria original) e que as amostras analisadas (Tabela 2) indicaram 90\% de MS para esse alimento, obteve-se o preço de R \$352,22/t de MS do cereal. Adotando-se como referencial o custo comparativo de $90 \%$ do valor do milho grão seco moído (MS) para a silagem de grãos úmidos, encontrou-se para esta silagem custo de R\$ 317,00/t de MS, equivalente a R \$234,58/t de matéria original (74\% MS).

Não há muita informação concernente aos custos de produção e às cotações de mercado para o sorgo, uma cultura ainda não muito explorada no país, proporcionalmente ao milho, e a maioria dos produtores deste cereal integraliza verticalmente sua produção para alimentação animal ou produção de álcool.

Contudo, Simas (1998) indicou como referência para este cereal o valor de 60 a $70 \%$ do preço do milho no mercado nacional. Duarte (2002), citando estudos da Embrapa, consi- derou como referencial o valor de $80 \%$ do preço do milho, valor adotado para determinação de custos neste experimento. Assim, considerando-se $80 \%$ do preço de $\mathrm{R} \$ 317,00 / \mathrm{t}$ MO de milho, obteve-se o valor de R\$253,60/t MO e, conseqüentemente, R $\$ 284,94 / t$ MS dos sorgos usados (Tabela 4).

Adotando-se os mesmos referenciais usados no cálculo do custo da silagem de grãos úmidos de milho para os sorgos, encontrou-se para a silagem de grãos úmidos do sorgo com tanino (74\% MS) o valor de R $\$ 256,45 /$ MS e $\mathrm{R} \$ 189,77 / \mathrm{t}$ MO e, para a do sorgo sem tanino (69\% MS), o valor de R\$256,45/t MS e R\$176,95/t MO. Adotando-se o custo da ração (MS) com milho moído como referencial (100\%), observou-se o menor custo comparativo na ração com silagem de grãos úmidos de sorgo sem tanino (89,1\%).

$\mathrm{Na}$ análise de custos da criação dos bezerros até o desaleitamento, foram avaliados os custos operacionais efetivos das rações, do sucedâneo e dos medicamentos em cada tratamento. As despesas com medicamentos foram muito homogêneas entre os tratamentos, uma vez que a dieta líquida, as práticas de manejo, as vacinações, as vermifugações e as instalações foram iguais para todos os animais.

Tabela 4 - Preços do sucedâneo e dos ingredientes e custos das rações concentradas

\begin{tabular}{|c|c|c|c|}
\hline Ingrediente & $\begin{array}{c}\text { Preço } \\
\left(\mathrm{R} \$ / \mathrm{kg} \mathrm{MN}^{1}\right)\end{array}$ & \multicolumn{2}{|c|}{$\begin{array}{c}\text { Preço } \\
\text { (R\$/kg MS) }\end{array}$} \\
\hline Sucedâneo de leite em pó & 2,32 & \multicolumn{2}{|c|}{2,52} \\
\hline Milho seco moído & 0,32 & \multicolumn{2}{|c|}{0,35} \\
\hline $\mathrm{SGU}^{2}$ de milho & 0,24 & \multicolumn{2}{|c|}{0,32} \\
\hline Sorgo seco com tanino moído & 0,25 & \multicolumn{2}{|c|}{0,29} \\
\hline $\mathrm{SGU}^{2}$ de sorgo com tanino & 0,19 & \multicolumn{2}{|c|}{0,26} \\
\hline & 0,25 & \multicolumn{2}{|c|}{0,29} \\
\hline $\mathrm{SGU}^{2}$ de sorgo sem tanino & 0,18 & \multicolumn{2}{|c|}{0,26} \\
\hline Farelo de soja & 0,61 & \multicolumn{2}{|c|}{0,68} \\
\hline Núcleo mineral e vitamínico & 1,55 & \multicolumn{2}{|c|}{1,55} \\
\hline Palatabilizante/aromatizante & 2,56 & \multicolumn{2}{|c|}{2,78} \\
\hline $\begin{array}{c}\text { Custo } \\
\left(\mathrm{R} \$ / \mathrm{kg} \mathrm{MO}^{1}\right)\end{array}$ & $\begin{array}{c}\text { Custo } \\
(\%)\end{array}$ & $\left.\mathrm{MS}^{2}\right)$ & $\begin{array}{l}\text { Custo } \\
(\%)\end{array}$ \\
\hline 0,57 & 100,0 & 62 & 100,0 \\
\hline SGUM & 86,5 & 61 & 97,6 \\
\hline SCTM & 91,5 & 58 & 92,5 \\
\hline SGUSCT & 80,2 & 56 & 90,4 \\
\hline SSTM & 91,7 & 57 & 92,1 \\
\hline SGUSST & 74,7 & 56 & 89,1 \\
\hline Dieta líquida & Custo $(\mathrm{R} \$ / \mathrm{l}$ & & \\
\hline Sucedâneo + gás & 0,25 & & \\
\hline
\end{tabular}

1 Matéria natural.

2 Silagem de grãos úmidos.

MM - milho seco moído; SGUM - silagem de grãos úmidos de milho; SCTM - sorgo seco com tanino moído, SGUSCT - silagem de grãos úmidos de sorgo com tanino; SSTM - sorgo seco sem tanino moído, SGUSST - silagem de grãos úmidos de sorgo sem tanino.

Cotação do dólar: US\$1,00 = R\$2,60. 
Os casos de diarréias e eventuais infestações por carrapatos ocorreram de forma similar em todos os tratamentos e, por isso, considerou-se o mesmo custo com medicamentos (Tabela 5).

Embora não tenham sido encontradas diferenças significativas $(\mathrm{P}>0,05)$ para nenhuma das variáveis analisadas no experimento, as diferenças numéricas de consumo e ganho de peso entre os tratamentos conferem, sob o prisma econômico, perspectivas de produção com maiores ou menores possibilidades de êxito, o que é fundamental na adoção de qualquer tecnologia de produção.

O consumo médio de MS de ração variou de 26,23 kg/ bezerro (dieta com silagem de grãos úmidos de sorgo sem tanino) a 43,84 kg/bezerro (dieta com o sorgo sem tanino na forma de grãos secos moídos). Do mesmo modo, o ganho de peso por animal também variou de 21,48 a 28,28 kg para essas mesmas dietas, respectivamente.

Essa diferença não-significativa $(\mathrm{P}>0,05)$ de consumo pode estar parcialmente relacionada ao fato de a silagem de grãos úmidos de sorgo sem tanino ter apresentado o menor teor de MS (69,0\%) entre os alimentos, o que pode ter ocasionado efeito deletério, em termos de fermentação do material, comprometendo sua aceitabilidade.

Apesar de terem apresentado, numericamente, os menores consumos e ganhos de peso, os animais alimentados com silagem de grãos úmidos de sorgo sem tanino foram

Tabela 5 - Análise de custos na criação dos bezerros com as rações concentradas até o desaleitamento

\begin{tabular}{|c|c|c|c|c|c|c|c|c|c|}
\hline Item & \multicolumn{6}{|c|}{ Ração concentrada } & Média & $\mathrm{CV} \%$ & Valor de $\mathrm{P}$ \\
\hline Consumo total ração (kg MS) & 35,96 & 33,45 & 41,08 & 30,03 & 43,84 & 26,23 & 35,10 & 29,60 & $\mathrm{~ns}^{1}$ \\
\hline Consumo total (kg MS) & 60,58 & 59,68 & 64,48 & 55,48 & 69,39 & 49,63 & 59,87 & 19,96 & ns \\
\hline Ganho total de peso (kg) & 22,66 & 23,24 & 24,34 & 25,34 & 28,28 & 21,48 & 24,22 & 29,52 & ns \\
\hline Dias no experimento & 62,20 & 63,80 & 60,60 & 62,40 & 63,80 & 58,40 & 61,87 & 19,96 & ns \\
\hline sucedâneo/L(R\$) & 0,25 & 0,25 & 0,25 & 0,25 & 0,25 & 0,25 & 0,25 & - & - \\
\hline sucedâneo/bezerro (R\$) & 65,59 & 69,85 & 62,30 & 67,77 & 68,04 & 62,33 & 65,98 & 16,34 & ns \\
\hline medicamento/bezerro (R\$) & 9,00 & 9,00 & 9,00 & 9,00 & 9,00 & 9,00 & 9,00 & - & - \\
\hline final/bezerro $(\mathrm{R} \$)$ & 96,99 & 99,19 & 94,96 & 93,68 & 102,24 & 85,89 & 95,49 & 14,14 & ns \\
\hline kg ganho/bezerro (R\$) & 4,28 & 4,27 & 3,90 & 3,70 & 3,62 & 4,00 & 3,96 & 29,88 & ns \\
\hline
\end{tabular}

MM - milho seco moído; SGUM - silagem de grãos úmidos de milho; SCTM - sorgo seco com tanino moído, SGUSCT - silagem de grãos úmidos de sorgo com tanino; SSTM - sorgo seco sem tanino moído, SGUSST - silagem de grãos úmidos de sorgo sem tanino.

${ }^{1}$ Não-significativo - P>0,05. Cotação do dólar: US $\$ 1,00=R \$ 2,60$.

o que se mantiveram por menos tempo (58,4 dias) no experimento e aqueles alimentados com silagem de grãos úmidos de milho e sorgo sem tanino moído foram os que demoraram mais para serem desaleitados (63,8 dias).

Os custos com sucedâneo se mantiveram entre R $\$ 62,30$ por bezerro no tratamento com sorgo com tanino moído e R \$ 69,85 por bezerro no tratamento com silagem de grãos úmidos de milho. Campos et al. (1996) desaleitaram bezerros com custo de R\$54,63 com sucedâneo, contudo, os animais foram desaleitados com menor idade (49 dias).

O menor custo por bezerro foi obtido no tratamento com silagem de grãos úmidos de sorgo sem tanino $(\mathrm{R} \$ 85,89)$ e o maior custo $(\mathrm{R} \$ 102,24)$ com o mesmo sorgo em grãos secos moídos. Contudo, considerando o custo por kg de ganho de peso (GP) vivo por bezerro no experimento, análise mais importante no contexto, observou-se que os animais do tratamento com sorgo sem tanino moído foram mais eficientes e que apresentaram os menores custos
( $R$ \$3,62/kg GP), enquanto os animais do tratamento com milho moído e silagem de grãos úmidos de milho foram os menos eficientes (R \$ 4,28 e R \$ 4,27/kg GP).

Ao optar por qualquer um dos componentes avaliados, é necessário considerar que as silagens de grãos úmidos apresentam custos menores que seus respectivos grãos secos moídos, no entanto, exigem preparo diário da ração, pois não é possível fazer estoques de rações, o que pode ser uma limitação para os sistemas de produção.

\section{Conclusões}

O sorgo com ou sem tanino, nas formas de grãos secos moídos ou silagem de grãos úmidos, e a silagem de grãos úmidos de milho podem ser usados em rações para bezerros holandeses até o desaleitamento, pois não prejudicam seu desempenho e conferem os mesmos resultados obtidos com o milho seco moído. 


\section{Literatura Citada}

AlmeidA JR., G.A.; CostA, C.; MONTEIRO, A.L.G. et al. Desempenho, características de carcaça e resultado econômico de cordeiros criados em creep feeding com silagem de grãos úmidos de milho. Revista Brasileira de Zootecnia, v.33, n.4, p.1048-1059, 2004.

ANDERSON, K.L.; NAGARAJA, T.G.; MORRIL, J.L. Ruminal metabolic development in calves weaned conventionally or early. Journal of Dairy Science, v.70, n.5, p.1000-1005, 1987.

AROEIRA, L.J.M.; PACIULLO, D.S.C. Produção de leite a pasto. Informe Agropecuário, v.25, n.221, p.56-63, 2004.

ASSOCIAÇÃO BRASILEIRA DOS CRIADORES DE BOVINOS DA RAÇA HOLANDESA - ABCBRH. [2005]. O gado holandês: o padrão da raça e as características. Disponível em: <http://www.gadoholandes. com.br/origem/araca. htm> Acesso em: 14/10/2005.

BAGALDO, A.R.; PIREZ, A.V.; MEYER, P.M. et al. Desempenho pós-desaleitamento de bezerros holandeses que receberam sucedâneo ou leite integral e milho floculado no concentrado inicial. Revista Brasileira de Zootecnia, v.35, n.3, p.857862, 2006.

BUtOlO, J.E. Sorgo. In: BUTOLO, J.E. (Ed.) Qualidade de ingredientes na alimentação animal. Campinas: $O$ Estado de São Paulo, 2002. p.202-215.

CALDAS, F. Vitelo: opção de ganho na exploração leiteira. Revista Balde Branco, v.38, n.461, p.36-40, 2003.

CAMPOS, O.F.; LIZIEIRE, R.S.; SPALLA, R.G. et al. Experimento do CNPGL/EMBRAPA com abate de machinhos da raça holandesa aos 6 meses de idade apresenta bons resultados. Gado Holandês, v.451, p.36-45, 1996.

DUARTE, J.O. Cultivo do sorgo: mercado e comercialização. [2002]. Disponível em: <http://sistemasdeproducao.cnptia.embrapa. br/FontesHTML/Sorgo/CultivodoSorgo/mercado.htm> Acesso em: 08/10/2005.

HUNTINGTON, G.B. Starch utilization by ruminants. From basics to the brink. Journal of Animal Science, v.75, n.3, p.852867, 1997.

INSTITUTO AGRONÔMICO DE CAMPINAS - IAC. SANEST (Sistema de Análise Estatística). Campinas: 1992. (CD-ROM).

MACHADO NETO, R.; CASSOLI, L.D.; BESSI, R. et al. Avaliação do fornecimento adicional de colostro para bezerros. Revista Brasileira de Zootecnia, v.33, n.2, p.420-425, 2004a.
MACHADO NETO, R.; FARONI, C.E.; PAULETTI, P. et al. Levantamento do manejo de bovinos leiteiros recém-nascidos: desempenho e aquisição de proteção passiva. Revista Brasileira de Zootecnia, v.33, n.6, p.2323-2329, 2004b (supl. 3).

MODESTO, E.C.; MANCIO, A.B.; MENIN, E. et al. Desempenho produtivo de bezerros desmamados precocemente alimentados com diferentes dietas líquidas com utilização de promotor de crescimento. Revista Brasileira de Zootecnia, v.31, n.1, p.429-435, 2002 (supl.).

NATIONAL RESEARCH COUNCIL - NRC. Nutrient requeriments of dairy cattle. 6.rev.ed. Washington, D.C.: National Academy Press, 1988. 157p.

NUSSIO, C.M.B.; SANTOS, F.A.P.; ZOPOLLATTO, M. et al. Parâmetros de fermentação e medidas morfométricas dos compartimentos ruminais de bezerros leiteiros suplementados com milho processado (floculado vs. laminado a vapor) e monensina. Revista Brasileira de Zootecnia, v.32, n.4, p.1021-1031, 2003a.

NUSSIO, C.M.B.; SANTOS, F.A.P.; ZOPOLLATTO, M. et al. Processamento de milho (floculado vs. laminado a vapor) e adição de monensina para bezerras leiteiras, pré e pós-desmama precoce. Revista Brasileira de Zootecnia, v.32, n.1, p.229-239, 2003b.

OWENS, F.N.; ZINN, R.A.; KIM, Y.K. Limits to starch digestion in the ruminant small intestine. Journal of Animal Science, v.63, n.5, p.1634-1648, 1986.

RIBEIRO, T.R.; PEREIRA, J.C.; OLIVEIRA, M.V.M. et al. Influência do plano nutricional sobre o desempenho de bezerros holandês para produção de vitelos. Revista Brasileira de Zootecnia, v.30, n.6, p.2145-2153, 2001 (supl.).

SIGNORETTI, R.D.; ARAÚJO, G.G.L.; SILVA, J.F.C. et al. Composição física da carcaça de bezerros da raça holandesa alimentados com dietas contendo diferentes níveis de concentrado. Revista Brasileira de Zootecnia, v.28, n.4, p.883-888, 1999.

SIMAS, J.M.C. Sorgo e milho em flocos são alternativas viáveis. Agropecuária Hoje, v.4, n.20, p.4, 1998.

TEIXEIRA, J.C.; SANTOS, R.M.; PEREZ, J.R.O. et al. Aproveitamento do macho leiteiro utilizando dietas à base de amiréia 45S. I. Biometria do trato gastrointestinal e características de carcaça. Ciência e Agrotecnologia, v.23, n.2. p.421-426, 1999.

THEURER, C.B. Grain processing effects on starch utilization by ruminants. Journal of Animal Science, v.63, n.5, p.16491662, 1986. 